\title{
Friction Behavior of a Multi-Interface System and Improved Performance by $\mathrm{AlMgB}_{14}-\mathrm{TiB}_{2}-\mathrm{C}$ and Diamond-Like-Carbon Coatings
}

\author{
Jun $\mathrm{Qu}^{1, *}$, Peter J. Blau ${ }^{1, \#}$, Clifton Higdon ${ }^{2}$, and Bruce A. Cook ${ }^{3, \&}$ \\ ${ }^{1}$ Materials Science and Technology Division, Oak Ridge National Laboratory \\ ${ }^{2}$ Quality at Bluewater Thermal Solutions \\ ${ }^{3}$ Division of Materials Science \& Engineering, Ames Laboratory
}

\begin{abstract}
This study investigated friction behavior of a bearing system with two interfaces involved: a roller component experiencing rolling-sliding interaction against twin-cylinders under point contacts while simultaneously undergoing pure sliding interaction against a socket under a conformal contact. Lubrication modeling predicted a strong correlation between the roller's rolling condition and the system's friction behavior. Experimental observations first validated the analytical predictions using steel and iron components. Diamond-like-carbon (DLC) coating and $\mathrm{AlMgB}_{14}-\mathrm{TiB}_{2}$ coating with a carbon topcoat (BAMC) were then applied to the roller and twin-cylinders, respectively. Testing and analysis results suggest that the coatings effectively decreased the slip ratio for the roller-cylinder contact and the sliding friction at both bearing interfaces and, as a result, significantly reduced the system frictional torque.
\end{abstract}

Keywords: multi-interface system; $\mathrm{AlMgB}_{14}-\mathrm{TiB}_{2}$; DLC; rolling-sliding

\footnotetext{
* Corresponding author, P.O. Box 2008, MS-6063, Oak Ridge, TN 37830-6063, tel: (865) 576-9304, fax: (865) 5744913, qujn@ornl.gov

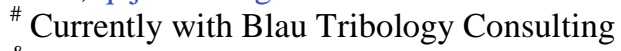

${ }^{\&}$ Currently with Material Dynamics and Devices, Inc.
} 


\subsection{Introduction}

A variety of advanced coatings have recently been developed for reducing friction and wear [1,2]. The majority of lab-scale friction results of these coatings in the literature were obtained from tribological tests that involved only one primary interface. However, in many actual bearing systems, the triboelements are in contact with more than one counterface simultaneously. A classic example is bearing balls rolling against both the inner and outer rings and, at the same time, sliding against the cage on the side. In such a case, the frictional torque experienced by the ball is a combination from all three contact points.

The purpose of the current work was to investigate the effect of two advanced coatings on the friction behavior when used together in a tribosystem composed of two interfaces. One interface involves rollingsliding under a point contact while the other involves pure sliding under a conformal contact. Interfaces of this kind can be found in a variety of industrial hydraulic machinery. One coating is a commercial diamond-like-carbon (DLC) [3-7]. The other is a recently-developed two-layer coating. The top layer consisted primarily of sp2 bonded carbon and the base layer was $\mathrm{AlMgB}_{14}-(50$ vol\% $) \mathrm{TiB}_{2}$. This coating is denoted as BAMC here. Single-phase amorphous $\mathrm{AlMgB}_{14}$ thin films produced by pulse-laser-deposition were reported with a high nanoindentation hardness of $>30 \mathrm{GPa}[8,9]$. The $\mathrm{AlMgB}_{14}-\mathrm{TiB}_{2}$ composite coating was later developed by physical vapor deposition (PVD), and demonstrated high wear resistance [10-12]. Correlated results from lubrication modeling and friction bench testing suggest that using the BAMC and DLC together would minimize the slip ratio at the rolling-sliding contact and reduce the sliding friction at both interfaces. As a result, the frictional torque of the entire bearing tribosystem is significantly reduced.

\subsection{Materials and Experimental}

A multi-interface bench test was carefully designed with two bearing contacts, as illustrated in Fig. 1. The top component is a socket, inserted into which is a roller that crossly sits on a pair of twin cylinders. The socket is under reciprocating sliding. Following the motion of the socket, the roller component rolls 
and/or slides back and forth against the twin-cylinders on the bottom. The center velocity of the roller always is the same as that of the socket, $V_{\text {roller_center }}=V_{\text {socket }}$, and the relative velocity at the roller-socket

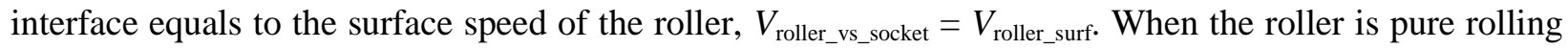
against the cylinder, there is no relative motion at the roller-cylinder contact, $V_{\text {roller_vs_cylinder }}=V_{\text {roller_bottom }}=$ 0 . Since the roller center speed is the average of the roller top and bottom speeds, $V_{\text {roller_center }}=\left(V_{\text {roller_top }}+\right.$ $\left.V_{\text {roller_bottom }}\right) / 2$, the roller top speed is the twice of the roller center speed, $V_{\text {roller_top }}=2 \cdot V_{\text {roller_center }}=2 \cdot V_{\text {socket }}$, as illustrated in Fig. 1b. The roller top speed is a combination of the roller center speed and roller surface speed, $V_{\text {roller_top }}=V_{\text {roller_center }}+V_{\text {roller_surf }}$, therefore $V_{\text {roller_surf }}=V_{\text {roller_top }}-V_{\text {roller_center }}=V_{\text {roller_center. }}$. Thus, $V_{\text {roller_vs_socket }}=V_{\text {roller_center }}=V_{\text {socket. }}$ On the other hand, when the roller is stuck with the socket (no rolling, $V_{\text {roller_vs_socket }}=0$ ), the roller experiences a pure sliding against the twin cylinders and the relative speed at the roller-cylinder interface becomes the same as the socket speed, $V_{\text {roller_vs_cylinder }}=V_{\text {roller_center }}=V_{\text {socket }}$.

(a)

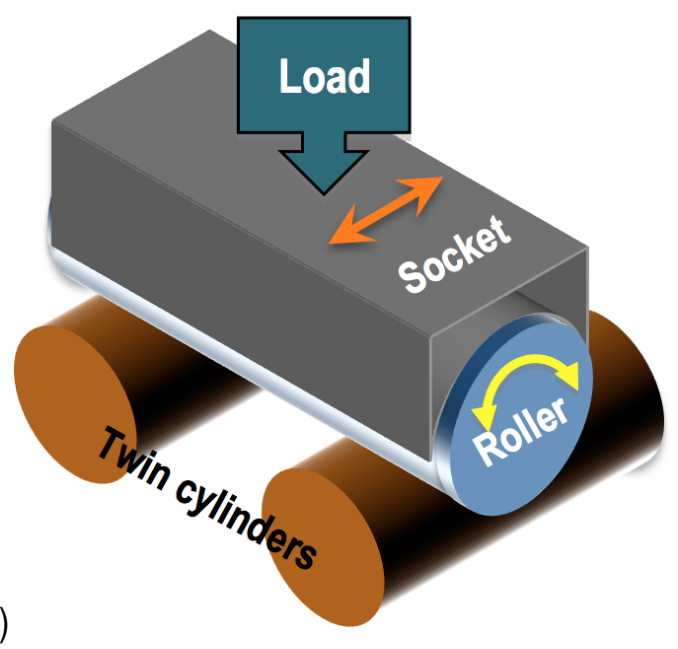

(b)

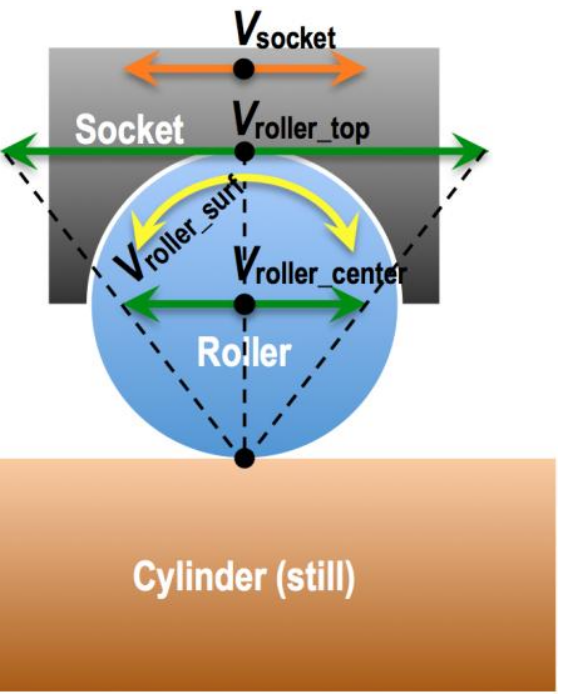

Fig. 1. Schematic of the multi-interface bench test. (a) 3D view and (b) 2D view with correlated component velocities at pure rolling between the roller and the cylinders.

The actual setup is on a reciprocating sliding tribotester (Plint model TE-77), as shown in Fig. 2. The socket is made of ductile iron with an inner radius of $6.356 \mathrm{~mm}$. The root-mean-square (RMS, $R_{\mathrm{q}}$ ) roughness of the inner cylindrical surface is $0.316 \mu \mathrm{m}$. The roller is made of through-hardened bearing 
steel with a diameter of $12.7 \mathrm{~mm}$ and RMS surface roughness of $0.085 \mu \mathrm{m}$. Both the roller and socket are $31.75 \mathrm{~mm}$ long. The twin cylinders are made of carburized steel and have a diameter of $9.525 \mathrm{~mm}$ and a length of $25.4 \mathrm{~mm}$ with RMS surface roughness of $0.406 \mu \mathrm{m}$. A DLC coating (modified a-C:H:W) was applied to the roller surface using a proprietary PVD (physical vapor deposition) process at HEF USA. The DLC coating has a mean thickness of $2.5 \mu \mathrm{m}$ and a mean HK hardness of $18.7 \mathrm{GPa}$. BAMC was PVD-coated on the twin cylinders using a proprietary process by our industrial partner. The average thicknesses of the $\mathrm{AlMgB}_{14}-\mathrm{TiB}_{2}$ and top carbon layers are 4.5 and $1.7 \mu \mathrm{m}$, respectively, as measured from the polished cross section. Knoop microindentations were conducted on the BAMC coating under a load of $100 \mathrm{~g}$-f, and the measured HK hardness was $13.3 \mathrm{GPa}$. The measured hardness of the two-layer BAMC coating reflects the combination of the harder boride base and a softer top carbon layer.



Fig. 2. Actual setup of the multi-interface bench test.

The test specimens were lubricated by a Mobil DTE-24 ${ }^{\mathrm{TM}}$ hydraulic fluid. Using a Petrolab MINIVIS II viscometer, its viscosities were measured as 60.3 and $6.8 \mathrm{cP}$ at room temperature $\left(23{ }^{\circ} \mathrm{C}\right)$ and $82.2{ }^{\circ} \mathrm{C}$, respectively. The viscosity-pressure (V-P) coefficient here is defined by the reciprocal asymptotic isoviscous pressure coefficient that is employed in the Dowson formula [13] for lubricant film thickness calculations. The V-P coefficient of this lubricant was determined using a high-pressure, high-temperature 
viscometer following the procedure described in Bair and Qureshi [14]. The measured V-P coefficient is 21.9 and $15.2 \mathrm{GPa}^{-1}$ at 23 and $82.2^{\circ} \mathrm{C}$, respectively.

Tests were carried out at room temperature $\left(23^{\circ} \mathrm{C}\right)$ with two normal loads, 10 and $60 \mathrm{~N}$, applied. The Hertzian contact stresses [15] at the roller-cylinder interface (point-contact) are 751 and $1364 \mathrm{MPa}$, respectively. Since the socket-roller contact is nearly conformal, the contact stress is expected to be rather low (estimated to be in the order of a few MPa). Six different oscillation frequencies were used: $0.05,0.1,0.25,0.5,0.75$, and $1 \mathrm{~Hz}$. Using a constant stroke of $10 \mathrm{~mm}$, the corresponding mean velocities of the socket $\left(V_{\text {socket }}\right)$ relative to the twin cylinders are $1,2,5,10,15$, and $20 \mathrm{~mm} / \mathrm{s}$, respectively. The tangential force was measured in situ using a piezoelectric force sensor mounted on the holder of the twin cylinders. The composite friction coefficient of the system is calculated by normalizing the tangential force on the cylinders with the normal load on the socket, and reflects a combined effect of the two bearing interfaces, socket-roller and roller-cylinder.

The lubrication regimes of the socket-roller and roller-cylinder interfaces were determined at different operation conditions by the ratio $(\lambda)$ between the lubricant film thickness $(h)$ and the composite roughness ( $\sigma$ ) at the contact area: $\lambda=\frac{h}{\sigma}$. The lubrication regime is commonly divided into four general categories [13]: boundary (BL, $\lambda<1$ ), mixed (ML, $1<=\lambda<3$ ), elastohydrodynamic (EHL, $3<=\lambda<10$ ), and hydrodynamic lubrication (HL, $\lambda>=10$ ). BL involves solid-solid asperity collisions resulting in a relatively high friction coefficient (usually 0.05-0.15) and material displacement or wear. On the other hand, an EHL/HL contact is fully separated by a liquid film and therefore has a much lower friction coefficient (usually $0.001-0.03$ ) with no wear. ML is the transition stage between BL and EHL. The lubricant film thickness $(h)$ was calculated using the Dowson formula [13]. In theoretical modeling, the minimum lubricant film thickness $\left(h_{\min }\right)$ is designated for the lambda ratio calculation. In practical situations, the central film thickness $\left(h_{\mathrm{c}}\right)$ is more often used because the lubricant film between the surfaces in relative motion has an almost constant thickness, and the central value can well represent 
much of the Hertzian contact zone [13]. The composite roughness is defined as $\sigma=\sqrt{\sigma_{1}^{2}+\sigma_{2}^{2}}$, where $\sigma_{1}$ and $\sigma_{2}$ are the root-mean-square (RMS) surface roughness of the two surfaces in contact. The composite roughness values for the socket-roller and roller-cylinder contacts are calculated to be 0.329 and 0.415 $\mu \mathrm{m}$, respectively.

\subsection{Results and Discussion}

\subsection{Predicted friction behavior by lubrication modeling}

The central lubricant film thicknesses and $\lambda$-ratios at the roller-cylinder and socket-roller contacts in the bench test were calculated using the mean sliding speed with the assumption of pure rolling at the roller-cylinder contact (Table 1). The socket-roller contact has its highest normal force on the central top and lowest force on the side. As a result, the lubricant film at the central top contact line of the socketroller interface is the thinnest and determines the lubrication regime; therefore, it was used in the analysis.

As shown in Table 1, the roller-cylinder interface is always in BL because of the relatively high contact stress (point contact). On the other hand, the socket-roller contact operates in BL at low oscillation frequencies $(<0.50 \mathrm{~Hz})$ and in ML at higher frequencies $(0.50-1.0 \mathrm{~Hz})$. The last two columns in Table 1 predict the slip ratio at the roller-cylinder contact and the system friction behavior. At the lowest oscillation frequency of $0.05 \mathrm{~Hz}$, both interfaces are in $\mathrm{BL}$ and the slip ratio and composite friction coefficient are expected to be high. As the oscillation accelerates, the $\lambda$ ratio of the socket-roller sliding interface increases and the lubrication regime eventually transitions from BL to ML, which is expected to reduce the roller-cylinder slip ratio resulting in a lower system friction. 
Table 1. Results of lubrication modeling of the two bearing interfaces.

\begin{tabular}{|c|c|c|c|c|c|c|c|}
\hline \multirow{2}{*}{$\begin{array}{l}\text { Load } \\
(\mathrm{N})\end{array}$} & \multirow{2}{*}{$\begin{array}{l}\text { Oscillation } \\
\text { frequency } \\
(\mathrm{Hz})\end{array}$} & \multicolumn{2}{|c|}{ Roller-cylinder } & \multicolumn{2}{|c|}{ Socket-roller } & \multirow{2}{*}{$\begin{array}{l}\text { Roller- } \\
\text { cylinder } \\
\text { slip ratio }\end{array}$} & \multirow{2}{*}{$\begin{array}{l}\text { Composite } \\
\text { friction } \\
\text { coefficien }\end{array}$} \\
\hline & & $h_{\mathrm{c}}{ }^{*}(\mu \mathrm{m})$ & $\lambda$ & $h_{\mathrm{c}}^{*}(\mu \mathrm{m})$ & $\lambda$ & & \\
\hline \multirow{3}{*}{10} & 0.05 & 0.003 & 0.007 (BL) & 0.07 & $0.20(\mathrm{BL})$ & \multirow{3}{*}{$\downarrow_{\text {Low }}^{\text {High }}$} & \multirow{3}{*}{$\underset{\text { Low }}{\downarrow}$} \\
\hline & 0.5 & 0.014 & $0.03(\mathrm{BL})$ & 0.32 & 0.98 (BL/ML) & & \\
\hline & 1.0 & 0.022 & 0.05 (BL) & 0.52 & 1.58 (ML) & & \\
\hline \multirow{3}{*}{60} & 0.05 & 0.003 & $0.006(\mathrm{BL})$ & 0.05 & $0.17(\mathrm{BL})$ & \multirow{3}{*}{$\downarrow_{\text {Low }}^{\text {High }}$} & \multirow{3}{*}{$\underset{\text { Low }}{\downarrow}$} \\
\hline & 0.75 & 0.016 & $0.04(\mathrm{BL})$ & 0.36 & 1.08 (BL/ML) & & \\
\hline & 1.0 & 0.020 & 0.05 (BL) & 0.43 & 1.32 (ML) & & \\
\hline
\end{tabular}

Lubricant film thickness was calculated for pure rolling at the roller-cylinder interface, and the actual film thickness may be lower due to slip.

\subsection{Friction behavior of the uncoated system verifying the modeling predictions}

Tests were first conducted on the uncoated system with the iron socket, steel roller, and steel cylinders, denoted as 'iron-steel-steel'. Figure 3a compares the friction behavior of two tests under oscillation frequencies of 0.05 and $1.0 \mathrm{~Hz}$, respectively. The friction coefficient at $0.05 \mathrm{~Hz}$ fluctuated between 0.19 and 0.28 (artificially dropping to 0.1 because of motion reversal at the stroke ends). In contrast, the test at $1.0 \mathrm{~Hz}$ generated a much lower friction coefficient of 0.035 with little variation. It was observed that the roller was in pure sliding against the twin cylinders at $0.05 \mathrm{~Hz}$, whereas it was rolling smoothly back and forth (low slip ratio) on the cylinders at $1.0 \mathrm{~Hz}$. This is believed to be responsible for the distinct friction behavior illustrated in Fig. 3a, and agrees very well with the modeling predicted behavior in Table 1.

The average friction coefficient and roller rolling behavior of the full test matrix for the uncoated system are summarized in Fig. 3b, and they largely agree with the modeling predictions in Table 1. For example, in the tests under a $10 \mathrm{~N}$ load, the roller exhibited pure sliding against the cylinders at $0.05 \mathrm{~Hz}$ and the friction coefficient was high $(>0.20)$. The roller started rolling at $0.10 \mathrm{~Hz}$ but with a high slip ratio, and the rolling condition improved (slip ratio decreasing) when the frequency increased to $0.50 \mathrm{~Hz}$. As a result, the composite friction coefficient decreased, along with the increasing speed, from above 0.20 to 
below 0.08 . At $0.5 \mathrm{~Hz}$ or higher, the roller rolled smoothly back and forth (low slip ratio), resulting in a low friction level of $0.03-0.07$.
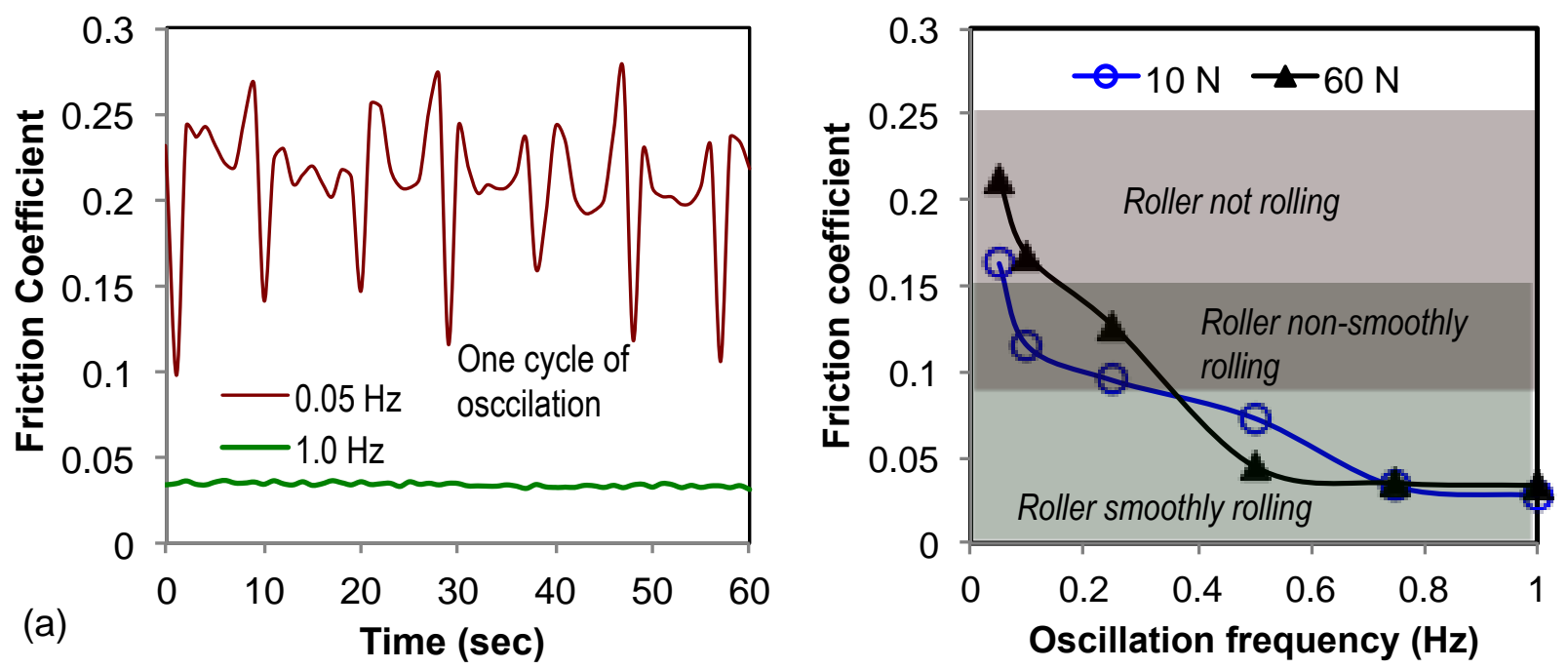

Fig. 3. Experimental results of the iron-steel-steel system correlate well with modeling predictions: (a) comparison of detailed friction behavior at low and high speeds under the same $60 \mathrm{~N}$ and (b) overall friction performance corresponding to the roller rolling behavior.

\subsection{Friction behavior of the coated system demonstrating effective friction reduction}

The set of iron socket, DLC-coated roller, and BAMC-coated twin cylinders is referred as "ironDLC-BAMC" here. Results of iron-DLC-BAMC were benchmarked against those of iron-steel-steel. The detailed friction behavior of the two material sets under a $60 \mathrm{~N}$ load at the oscillation frequencies of 0.05 and $0.25 \mathrm{~Hz}$ are presented in Figs. $4 \mathrm{a}$ and $4 \mathrm{~b}$, respectively. At $0.05 \mathrm{~Hz}$, the roller was in pure sliding against the twin cylinders for both material sets, but the coated set generated a much lower composite friction coefficient $(\mu=0.08)$ than the uncoated set $(\mu=0.21)$. At $0.25 \mathrm{~Hz}$, the roller in the iron-steel-steel test was rolling non-smoothly (high slip ratio) and the composite friction coefficient was around 0.12 with high fluctuation. In contrast, the roller in the iron-DLC-BAMC test was rolling very smoothly (low slip ratio) and the composite friction coefficient was at a much lower level ( 0.05).

The overall friction performance of the two material sets is compared in Figs. 4c and 4d. Clearly, the coatings significantly reduced the friction in all test conditions. The significantly improved friction 
performance by the coatings can be attributed to two factors: (1) the BAMC-DLC reduces the sliding friction compared with the steel-steel contact for the roller-cylinder interface, and (2) the iron-DLC contact provides a lower frictional resistance than the iron-steel contact at the socket-roller interface and, as a result, improves the roller's rolling condition (lower slip ratio) against the cylinder.
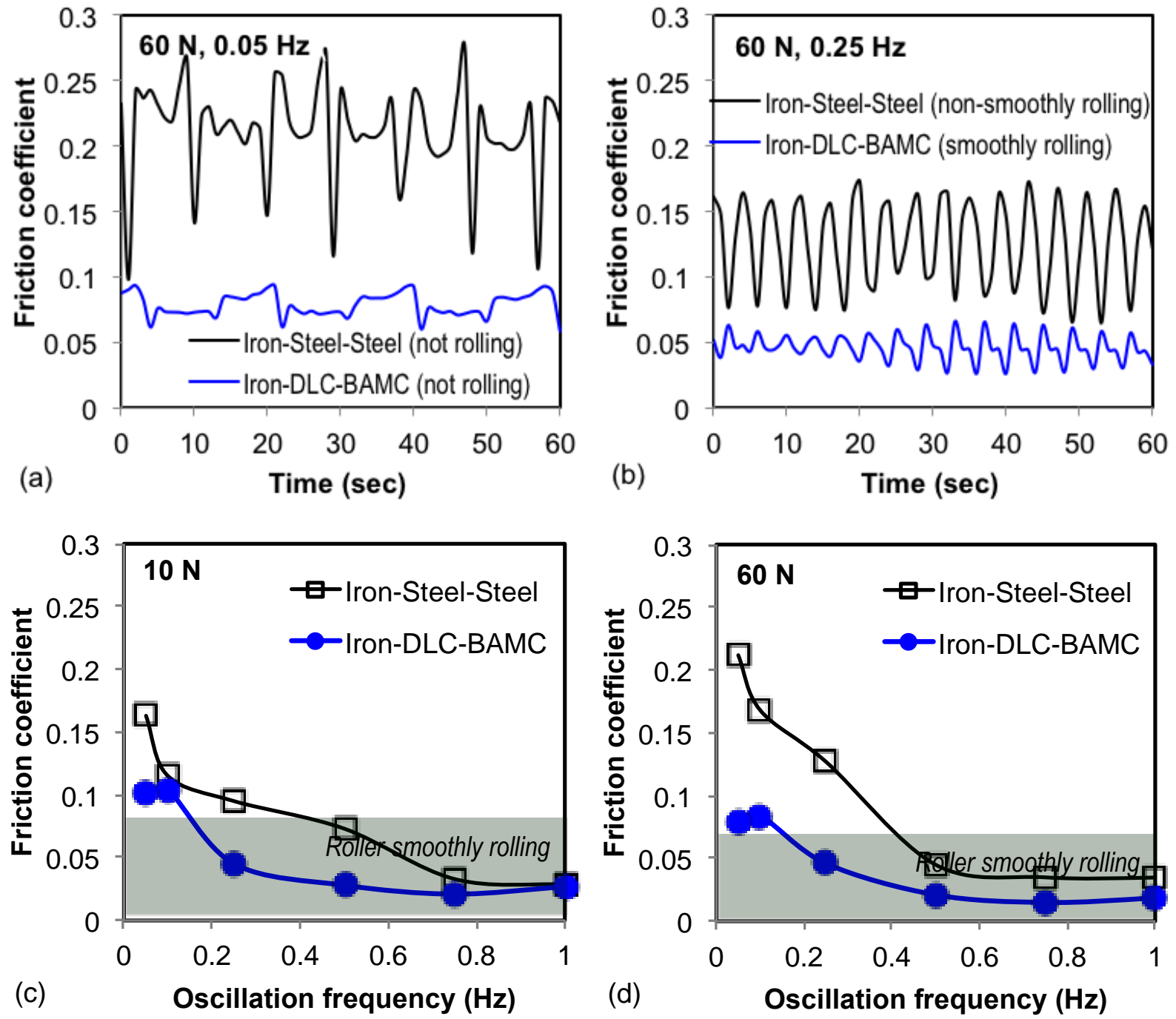

Fig. 4. Using the DLC and BAMC coatings effectively reduced friction. Comparison of detailed friction behavior ( $a$ and $b$ ) and overall friction performance of the full test matrix ( $c$ and $d$ ). 


\subsection{Conclusions}

This research effort developed and used a new, multi-contact bench friction test involving two bearing interfaces: a roller rolling-sliding against twin-cylinders under point contacts, and simultaneously, pure sliding mode against a socket under a conformal contact. Lubrication modeling suggests that the socket-roller sliding contact at lower speeds is in boundary lubrication with higher friction, causing a high slip ratio for the roller-cylinder rolling-sliding contact, which in turn leads to a high system frictional torque. The analytical predictions for friction and roller rolling behavior were validated in the bench tests using a steel roller, steel cylinders, and a cast iron socket. Two advanced coatings, BAMC and DLC, were applied to the roller and twin-cylinders and demonstrated significantly improved friction behavior compared with the uncoated material combination. The well-agreed analytical and experimental results suggested that the application of these two coatings can effectively decrease the sliding friction as well as improve the rolling characteristics.

\section{Acknowledgments}

Authors thank Dr. S. Bair at the Center for High-Pressure Rheology at Georgia Institute of Technology for measuring the viscosity-pressure coefficient of the lubricant. Research was supported by the U.S. Department of Energy, Office of Energy Efficiency and Renewable Energy, Industrial Technologies Program.

Notice: This manuscript has been authored by UT-Battelle, LLC, under Contract no. DE-AC05OOOR22725 with the US Department of Energy. The United States Government retains and the publisher, by accepting the article for publication, acknowledges that the United States Government retains a nonexclusive, paid-up, irrevocable, world-wide license to publish or reproduce the published form of this manuscript, or allow others to do so, for United States Government purposes.

\section{References}

[1] S Stewart, R Ahmed, Rolling contact fatigue of surface coatings - a review, Wear 253 (2002) 11321144.

[2] L. Wu, X. Guo, J. Zhang, Abrasive resistant coatings - a review, Lubricants 2 (2014) 66-89. 
[3] A. Grilla, V. Patela, B.S. Meyerson, Optical and tribological properties of heat-treated diamond-like carbon, Journal of Materials Research 5 (11) (1990) 2531-2537.

[4] D.S. Kim, T. E. Fischer, B. Gallois, The effects of oxygen and humidity on friction and wear of diamond-like carbon films, Surface and Coatings Technology 49 (1-3) (1991) 537-542.

[5] A. Grill, Review of the tribology of diamond-like carbon, Wear 168 (1-2) (1993) 143-153.

[6] A. Grill, Diamond-like carbon: State of the art, Diamond and Related Materials 8 (2-5) (1999) 428434.

[7] J.A. Heimberg, K.J. Wahl, I.L. Singer, A. Erdemir, Superlow friction behavior of diamond-like carbon coatings: Time and speed effects, Applied Physics Letters 78 (2001) 2449-2251.

[8] Y. Tian, A.F. Bastawros, C.C.H. Lo, A.P. Constant, A.M. Russell, B.A. Cook, Superhard selflubricating $\mathrm{AlMgB}_{14}$ films for microelectromechanical devices, Applied Physics Letters 83(14) (2003) 2781-2783.

[9] Y. Tian, A. Constant, C.C. Lo, J.W. Anderegg, A.M. Russell, J.E. Snyder, Microstructure evolution of Al-Mg-B thin films by thermal annealing, J. Vac. Sci. Technol. A 21 (2003) 1055.

[10] J. Qu, P.J. Blau, D. Zhu, B.A. Cook, and A.A. Elmoursi, Proceedings of IJTC2008 STLE/ASME International Joint Tribology Conference, Miami, FL, USA, October 20-22, 2008.

[11] B.A. Cook, J.L. Harringa, J.W. Anderegg, A.M. Russell, J. Qu, P.J. Blau, C.B. Higdon, A.A. Elmoursi, Analysis of wear mechanisms in low friction $\mathrm{AlMgB}_{14}-\mathrm{TiB}_{2}$ coatings, Surface \& Coatings Technology 205 (2010) 2296-2301.

[12] C. Higdon, B. Cook, J. Harringa, A. Russell, J. Goldsmith, J. Qu, P. Blau, Friction and wear mechanisms in $\mathrm{AlMgB}_{14}-\mathrm{TiB}_{2}$ nanocoatings, Wear 271 (2011) 2111-2115.

[13] B.J. Hamrock, D. Dowson, Ball Bearing Lubrication-The Elastohydrodynamics of Elliptical Contacts, a Wiley-Interscience Publication, John Wiley \& Sons, New York (1981).

[14] S. Bair, F. Qureshi, Accurate measurements of pressure-viscosity behavior in lubricants, Tribology Transactions 45 (2002) 390-396.

[15] W. Young, Roark's Formulas for Stress and Strain, $6^{\text {th }}$ Ed., Mcgraw-Hill, Texas (1989). 